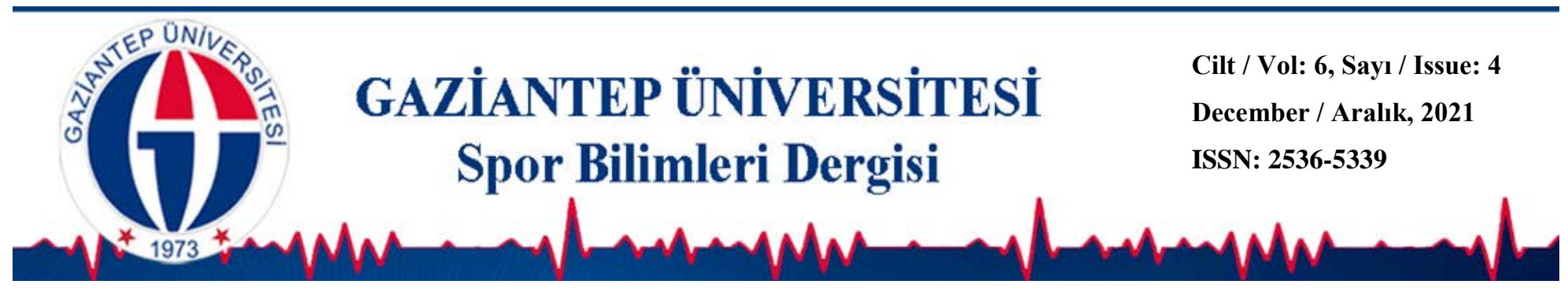

\title{
Aşırtmalı Aba Güreşi Müsabakalarında Müsabaka Süresi ile Üst Ekstremite Yorgunluğu Arasındaki İlişkinin İncelenmesi
}

\author{
Ahmet KOYUNLU ${ }^{1 *}$ iD \\ Murat BILGiÇ² iD \\ Mustafa ÖZDAL ${ }^{3}$ iD \\ ${ }^{1}$ Kahramanmaraș Sütçü İmam Üniversitesi, Türkoğlu Meslek Yüksekokulu, KAHRAMANMARAŞ \\ ${ }^{2}$ Batman Üniversitesi, Beden Eğitimi ve Spor Yüksekokulu, BATMAN \\ ${ }^{3}$ Gaziantep Üniversitesi, Spor Bilimleri Fakültesi, GAZİANTEP
}

DOI: $10.31680 / g a u n j s s .1031638$

Orijinal Makale / Original Article

Geliş Tarihi / Received: 11.11.2021 Kabul Tarihi / Accepted: 06.12.2021 Yayın Tarihi / Published: 24.12.2021

\section{Öz}

Bu çalışmanın amacı geleneksel spor dalları içerisinde yer alan aşırtmalı aba güreşi müsabakalarında müsabaka süresi ile üst ekstremite yorgunluğu arasındaki ilişkiyi araştırmaktır. Çalışmaya Gaziantep ilinde yapılan 2. Uluslararası Aşırtmalı Aba güreşi müsabakalarında mücadele eden Başpehlivan kategorisinde güreşen sporcular katıldı. Deneklere üst ekstremite kuvvetini belirlemek için pençe kuvveti ölçümleri yapıldı. Elde edilen verilerin istatistiksel olarak analiz edilmesinde SPSS paket programı (SPSS for Windows, sürüm 22.0, SPSS Inc., Chicago, Illinois, ABD) kullanıldı. Yapılan istatistiksel değerlendirmelerin neticesinde Aşırtmalı aba güreşinde müsabaka süresi artıkça güreşçilerin sağ ile sol el kavrama kuvvetinin azaldığı ve yorgunluğun arttığı tespit edildi. Müsabaka süresi ile sağ el kavrama kuvveti yorgunluğu arasında orta düzeyde pozitif yönlü anlamlı korelasyon ( $r: 0,474$; p:0,006); müsabaka süresi ile sol el kavrama kuvveti yorgunluğu arasında orta düzeyde pozitif yönlü anlamlı korelasyon $(r: 0,381 ; p: 0,032)$ olduğu belirlendi $(p<0,05)$. Sonuç olarak; aşırtmalı aba güreşinde el aşırtma tekniğinin kullanıması, muhtelif teknik uygulamalarının tatbiki sırasında kavrama kuvvetinin ön planda olması, dolayısıyla müsabakayı kazanmak adına güreş̧̧ilerin müsabakalarda harcamış olduğu eforun müsabaka süresi boyunca devam ettirme ve karşılaşma sırasında hem rakibin teknik uygulamalarına karşı koyabilmek hem de kendi teknik uygulamalarını eksiksiz gerçekleştirebilmek için harcamış olduğu çabanın üst ekstremite yorgunluğunu arttırdığı ve yorgunluk artı̧ına bağlı olarak uzun süren müsabakalarda performansın olumsuz yönde etkilenebileceği söylenebilir.

Anahtar Kelimeler: Aba güreşi, aşırtma, başpehlivan

\section{Investigation of the Relationship Between Competition Duration and Upper Extremity Fatigue in Overlap Aba Wrestling Competitions}

\begin{abstract}
The aim of this study is to investigate the relationship between the duration of the competition and upper extremity fatigue in the over-the-top aba wrestling competitions, which are among the traditional sports branches. Athletes wrestling in the category of Başpehlivan, who competed in the 2nd International Aba wrestling competitions held in Gaziantep, participated in the study. Paw strength measurements were made to determine the upper extremity strength of the subjects. SPSS package program was used for statistical analysis of the obtained data. As a result of the statistical evaluations, it was determined that the right and left hand grip strength of the wrestlers decreased and the fatigue increased as the duration of the competition increased in Overlap aba wrestling. There was a moderate positive significant correlation between the duration of the competition and right hand grip strength fatigue ( $r: 0.474 ; p: 0.006) ;$ It was determined that there was a moderate positive significant correlation $(r: 0.381 ; p: 0.032)$ between competition time and left hand grip strength fatigue $(p<0.05)$. As a result; The use of the overhand technique in plaited aba wrestling, the fact that the grip strength is at the forefront during the application of various technical applications, so the effort of the wrestlers in order to win the match is to continue throughout the competition and to be able to resist the opponent's technical applications during the match and to perform their own technical applications completely. It can be said that the effort spent increases the upper extremity fatigue and the performance may be adversely affected in long-lasting competitions due to the increase in fatigue.
\end{abstract}

Keywords: Aba wrestling, plagiarism, chief wrestler

\footnotetext{
*Sorumlu Yazar: Ahmet KOYUNLU
}

e-mail: koyunluahmet@gmail.com 


\section{Giriş}

Güreş sporu, Türk tarihi boyunca uygulanan önemli sporlardan biridir. Türkiye'nin değişik bölgelerinde yağlı güreş, karakucak, şalvar, kapışmalı aba güreşi, aşırtmalı aba güreşi vb. güreşler düzenlenmektedir. Güreş iki bireyin birbiri ile yaptıkları herhangi bir malzeme ve alet kullanmadan birbirlerine üstünlük kurmaya çalıştıkları gerçek manada er gibi uygulanan fiziksel ve zihinsel olarak yapılan aktivitelerin tümüne denir (Toksöz, 2011). Türk kültüründe ata sporu olarak benimsenen güreş sadece Türk toplumu tarafından değil dünyada da toplumların ilgisini çeken spor branşlarından bir tanesidir (Gümüş ve Barut, 2006). Ayrıca güreş; bütün vücut bölümlerinin birlikte çalışmasını gerektiren cesaret, hareket süresi, refleks, beceri, dayanıklılık ve kuvvet isteyen bir faaliyet ve spor branşıdır (Avcuoğulları, 1993).

Güreş sporu hem eski hem de modern Türk toplumlarının hepsi tarafından çok sevilen ve yaygın olarak tatbik edilen bir spor branşıdır. Tarihi dönemler içerisinde gün yüzüne çıkan yağlı güreş, aba güreşi, şalvar güreşi, kemer güreşi ve karakucak güreşi gibi farklı formlarda Türk toplumunda günümüze kadar yaşatılmıştır (Kahraman 1989, Yıldıran, 1999).

Günümüzde gerçekleştirilen aba güreşleri otantikliğini hiç bozmamış, sanayi, modern hayattan etkilenmemiş ve yeniliklere uğramamıştır. Sporun evrenselliği açısından aba güreşi, bazı bölgelerimizde daha yoğun olarak görünse de, dünyanın birçok bölgesinde benzer teknikleriyle yayılmıştır. Aba güreşi görünüş biçimi, uygulanan teknikler bakımından olimpik judo branşıyla benzerlikler göstermektedir (Keskin, 1978; Şahin, 1999).

El, tüm şekil ve boyutlardaki nesneleri kavramak, onlara kuvvet uygulamak ve karmaşık, ince kontrollü hareketlerin bir kombinasyonunu gerçekleştirmek için tasarlanmış yaklaşık $30^{\circ}$ dönme ve dönüşüm özgürlüğüne sahip 27 kemik ve 15 eklemden oluşan karmaşık bir anatomik sistemdir (Moran, 1989). El kavrama gücü, klinik (Gulke ve ark., 2007; Özer ve ark., 2017; Sande ve ark., 2001; Tredgett ve Davis, 2000) ve güçlü sporcular (Borges ve ark., 2009; Kraemer ve ark., 2001; Eylen ve ark., 2017) tarafından kullanılan genel bir terimdir ve ellerin oluşturabileceği kas gücü ile kuvveti ifade eder. Bireyin normal biyokinetik koşullar altında tüm parmak eklemlerinin, başparmakların ve bileklerin istemli fleksiyonu yoluyla uygulayabildiği maksimum kuvvetin sonucudur (Koley ve Yaday, 2009). 
Koyunlu A, Bilgiç M, Özdal M. (2021). Aşırtmalı Aba Güreşi Müsabakalarında Müsabaka Süresi ile Üst Ekstremite Yorgunluğu Arasındaki İlişkinin İncelenmesi. Gaziantep Üniversitesi Spor Bilimleri Dergisi, 6(4), 413-423.

Yapılan araştırmalarda, üst ekstremitenin fonksiyonel performansının ölçülebilmesinde el kavrama kuvvetinin güvenilir bir ölçüm aracı olduğu ortaya konulmuştur (Chang ve ark., 2010; Lermakov ve ark., 2016; Kim ve ark., 2018; MassyWestropp ve ark., 2011). El kavrama kuvvetinin aynı zamanda bütün vücudun sahip olduğu kuvvetin bir göstergesi olduğu vurgulanmaktadır (Efdal ve ark., 2020).

El kavrama kuvveti aletin veya rakibin uzuvlarının tutulması gibi aktiviteleri gerçekleştirmek için el kavrama kuvvetinin yüksek değerlerde olması sporcunun rakiplerine karşı uygulayacağı teknikleri daha etkili bir şekilde uygulamasına olanak sağlamaktadır (Nag ve ark., 2003; Kanbak ve Dağlığlu, 2020). Judo, kaya tırmanışı, halter ve güreş gibi içerisinde kavrama bulunan sporlarda el kavrama kuvvetinin oldukça önemli olduğu kavrama kuvveti ile yakından ilişkili olduğu spor branşlarıdır (Watts ve ark., 2003; Leyk ve ark., 2007; Pizzigalli ve ark., 2017; Pancar ve ark., 2020; Koyunlu ve ark., 2020). Judo ve aba güreşi branşında gerek itme gerekse çekmek hareketlerini uygulamak için el kavrama kuvvetinin büyük öneme sahip olduğu bir gerçektir (Ağaoğlu ve ark., 2001).

$\mathrm{Bu}$ amaçla çalışmamızda; aşırtmalı aba güreşi müsabakalarında müsabaka süresi ile üst ekstremite yorgunluğu arasındaki ilişki araştırıımıştır.

\section{Yöntem}

Çalışmaya Gaziantep ilinde yapılan 2. Uluslararası Aşırtmalı Aba güreşi müsabakalarına katılan Başpehlivan kategorisinde güreşen 16 sporcu gönüllü olarak katılmışıı. Çalışmamıza katılan bütün deneklere çalışma planı ve amacı hakkında gerekli bilgilendirme yapılmıştır. Deneklere bir beslenme programı ve antrenman planı uygulanmamıştır. Çalışmamıza katılan deneklerin müsabakaya başlamadan önce gerçekleştirilen tartıma sırasında ve her müsabaka sonunda el kavrama kuvvet ölçümleri alınmış ve kayıt edilmiştir.

\section{El kavrama kuvveti ölçümü:}

Çalışmaya katılan deneklerin el kavrama kuvveti belirlenmesi için el dinamometresi (Takei marka) ile ölçümler gerçekleştirilmiştir. İlk müsabaka öncesi 5 dakika ısınmadan sonra denek ayakta iken ölçüm yapılan kolu bükmeden ve vücuda temas etmeden kol vücuda 45 derecelik açı yaparken ölçümler alınmıştır. Her müsabaka bittikten hemen sonra denek ayakta iken ölçüm yapılan kolu bükmeden ve vücuda temas etmeden kol vücuda 45 derecelik açı yaparken ölçüm alınmıştır. Bu 
Koyunlu A, Bilgiç M, Özdal M. (2021). Aşırtmalı Aba Güreşi Müsabakalarında Müsabaka Süresi ile Üst Ekstremite Yorgunluğu Arasındaki İlişkinin İncelenmesi. Gaziantep Üniversitesi Spor Bilimleri Dergisi, 6(4), 413-423.

durum her iki el kuvveti için 3 defa tekrar edilerek ve en yüksek değer kayıt edilmiştir (Özer, 2013).

\section{Verilerin Analizi:}

Araştırma sonunda elde edilen verilerin; tasnif edilmesinde ve yüzdelik farkların hesaplanmasında Excel programı (Microsoft Office, sürüm 2013, Microsoft Corp., Redmond, WA, ABD), istatistiksel olarak analiz edilmesinde ise SPSS paket programı (SPSS for Windows, sürüm 22.0, SPSS Inc., Chicago, Illinois, ABD) kullanıldı. Veriler ortalama, standart sapma olarak sunuldu. Normallik sınaması için Shapiro-Wilk testi uygulandı. Normal dağılım göstermeyen veri setleri için çarpıklık ve basıklık değerleri kontrol edildi ve \pm 2 değeri içinde olan veri setlerinin normal dağılım gösterdiği kabul edildi. İstatistiksel sonuçlar 0,05 anlamlılık düzeylerinde değerlendirildi. Pearson korelasyon testi ile veriler arasındaki ilişki incelendi.

\section{Bulgular}

Aşırtmalı aba güreşi müsabakalarında müsabaka süresi ile üst ekstremite yorgunluğu arasındaki ilişkinin incelendiği bu çalışmada elde edilen bulgular aşağıdaki tablolarda belirtilmiştir.

Tablo 1. Müsabakalarda elde edilen verilerin tanımlayıcı özellikleri

\begin{tabular}{cccccc}
\hline & N & Min. & Mak. & Ort. & Std. S. \\
\hline Müsabaka Süresi (sn) & 32 & 42,00 & 590,0 & 180,1 & 160,2 \\
Sağ El Kavrama Yorgunluğu (kg) & 32 & 0,03 & 18,03 & 4,99 & 4,15 \\
Sol El Kavrama Yorgunluğu (kg) & 32 & $-1,07$ & 10,98 & 3,47 & 3,83 \\
\hline
\end{tabular}

Tablo 1 araştırmaya katılan gönüllülerin müsabakalarda elde edilen verilerin tanımlayıcı bilgileri incelendiğinde müsabaka süresinin minimum 42,00 sn., maksimum 590,00 sn. ve ortalama olarak $180,13 \pm 160,21$ sn., sağ el kavrama yorgunluğunun

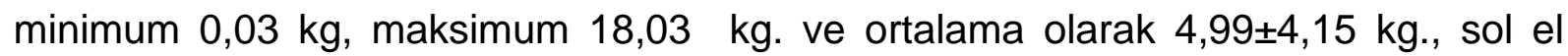
kavrama yorgunluğunun minimum $-1,07 \mathrm{~kg}$, maksimum 10,98 kg. ve ortalama olarak $3,47 \pm 3,83 \mathrm{~kg}$. olduğu tespit edilmiştir. 
Koyunlu A, Bilgiç M, Özdal M. (2021). Aşırtmalı Aba Güreşi Müsabakalarında Müsabaka Süresi ile Üst Ekstremite Yorgunluğu Arasındaki İlişkinin İncelenmesi. Gaziantep Üniversitesi Spor Bilimleri Dergisi, 6(4), $413-423$

Tablo 2. Müsabaka süreleri ile sağ ve sol el kavrama yorgunluğu arasındaki ilişki

\begin{tabular}{|c|c|c|c|c|}
\hline & & $\begin{array}{l}\text { Müsabaka } \\
\text { Süresi }\end{array}$ & $\begin{array}{c}\text { Sağ El Kavrama } \\
\text { Yorgunluğu }\end{array}$ & $\begin{array}{l}\text { Sol El Kavrama } \\
\text { Yorgunluğu }\end{array}$ \\
\hline Müsabaka Süresi & $\begin{array}{l}r \\
p\end{array}$ & 1 & $\begin{array}{l}0,474^{*} \\
0.006^{*}\end{array}$ & $\begin{array}{l}0,381^{*} \\
0.032^{*}\end{array}$ \\
\hline Sağ EI Kavrama Yorgunluğu & r & & 1 & $\begin{array}{l}0,315 \\
0,079\end{array}$ \\
\hline Sol El Kavrama Yorgunluğu & $\begin{array}{l}\mathrm{r} \\
\mathrm{p}\end{array}$ & & & 1 \\
\hline
\end{tabular}
${ }^{*}=\mathrm{p}<0,05$

Tablo 2 incelendiğinde müsabaka süresi arttıkça güreşçilerin sağ ve sol el kavrama kuvvetinin de azaldığı ve yorgunluğun arttığı tespit edilmiştir. Müsabaka süresi ile sağ el kavrama kuvveti yorgunluğu arasında orta düzeyde pozitif yönlü anlamlı korelasyon (r:0,474; p:0,006); müsabaka süresi ile sol el kavrama kuvveti yorgunluğu arasında orta düzeyde pozitif yönlü anlamlı korelasyon (r:0,381; p:0,032) olduğu belirlenmiştir $(p<0,05)$.

\section{Tartışma ve Sonuç}

Yapmış olduğumuz çalışmada müsabaka süresinin minimum $42,00 \mathrm{sn}$., maksimum 590,00 sn. ve ortalama olarak 180,13 $\pm 160,21$ sn., sağ el kavrama yorgunluğunun minimum $0,03 \mathrm{~kg}$, maksimum $18,03 \mathrm{~kg}$. ve ortalama olarak $4,99 \pm 4,15$ kg., sol el kavrama yorgunluğunun minimum $-1,07 \mathrm{~kg}$, maksimum 10,98 kg. ve ortalama olarak $3,47 \pm 3,83 \mathrm{~kg}$. olduğu tespit edilmiştir. Müsabaka süresi ile sağ el kavrama kuvveti yorgunluğu arasında orta düzeyde pozitif yönlü anlamlı korelasyon (r:0,474; p:0,006); müsabaka süresi ile sol el kavrama kuvveti yorgunluğu arasında orta düzeyde pozitif yönlü anlamlı korelasyon ( $r: 0,381 ; p: 0,032)$ olduğu belirlenmiştir $(p<0,05)$.

Artur ve arkadaşlarının sportif kaya tırmanışı sırasında tırmanıcıların yorgunluk durumlarındaki değişiklikleri incelediği araştırmasında maksimal el kavrama gücü yorgunluğunu minumun -1,53 maksimum $3.40 \mathrm{MVC} \mathrm{kk} / \mathrm{kg}$ olarak bulmuştur (Artur, 2019).

Watt ve arkadaşlarının sürekli sportif kaya tırmanışı ile kavrama gücü, dayanıkılık ve kan laktatında akut değişiklikler ile ilgili çalışmasında tırmanış öncesinden tırmanış sonrasına kadar el kavrama gücünde yüzde 22 ve kavrama dayanıklılığında yüzde 57 azalma olduğunu bildirmişlerdir (Watt ve ark., 1996). Gajewski ve ark. simüle edilmiş tırmanma yarışmasına yanıt olarak kavrama gücü ve kan laktatındaki değişiklikleri araştırmışlar ve el kavrama kuvvetinin tırmanıştan önceki 
Koyunlu A, Bilgiç M, Özdal M. (2021). Aşırtmalı Aba Güreşi Müsabakalarında Müsabaka Süresi ile Üst Ekstremite Yorgunluğu Arasındaki İlişkinin İncelenmesi. Gaziantep Üniversitesi Spor Bilimleri Dergisi, 6(4), $413-423$.

$7.39 \pm 1.30 \mathrm{~N} / \mathrm{kg}$ 'dan tırmanmadan 1 dakika sonra $6.57 \pm 1.05 \mathrm{~N} / \mathrm{kg}$ 'a önemli ölçüde azaldığını belirtmişlerdir (Gajewski ve ark., 2009).

Dövüş sporları gibi branşlarda gün içerisinde birden fazla müsabaka yapıldığından sporcuların nabız değerlerinde bir yükselme kuvvet değerlerinde ise düşüş ortaya çıkarmakta ve çeyrek final, yarı final ve final maçlarına daha yorgun ve daha düşük performansla mücadeleye katıldıklarını ortaya çıkmıştır (Çalap ve ark., 2019).

Beyzbol, tırmanma, golf, hokey, kürek çekme, yüzme, tenis, halter, güreş gibi kavrama ve kuvvet uygulamasının önemli olduğu spor branşlarında yüksek derecede el kavrama kuvveti gerektirir. Araştırmacılar; kaya ve buz tırmanışı gibi performans aktivitelerden sonra el kavrama kuvveti değerleri, başlangıç değerinden önemli ölçüde daha düşük olduğunu belirtmişlerdir (Gürer ve ark., 2020; Artur ve ark., 2019; Watts ve ark., 1996). Güreş ve judo gibi birbirini izleyen müsabakaların sonunda el kavrama kuvvetinde yorgunluğa bağlı olarak azalmaların olduğunu bildiren kısıtlı sayıda çalışmalar mevcuttur (Rafael ve ark., 2021; Kons ve ark., 2020; Kons ve ark., 2020; Bonitch ve ark., 2012; Iglesias ve ark., 2003; Kraemer ve ark., 2001).

Vücutta enerji kaynaklarının azalması ve metabolik artıkların birikmesine bağı olarak yorgunluk başlar (Ersoy, 1991). Yorgunluğun oluşması kuvvet ve süratin eksilmesine sebep olurken, buna bağlı olarak reaksiyon zamanının yavaşlamasına, müsabaka esnasında hataların artmasına, motor koordinasyonunun kaybına, isteğin ve yeteneğin kısıtlı kalmasına sebep olmaktadır (Gabrıella, 1987; Moncintosh, 1991; Kalkan ve Dağlıoğlu, 2018). Kas yorgunluğunun yaklaşık olarak kas glikojeninin vücutta boşalma hızı ile birlikte bu düşüşe doğru orantıı olarak arttığını ortaya koyaktadır (Gandevia, 2001; Maughan ve Gleeson, 2004; Ament ve Gijsbertus, 2009). Kas yorgunluğu, bazı aktiviteler sırasında kasların çalışma kapasitelerini daha fazla devam ettiremeyip, belirli süreliğine uygulanan performansta düşme yaşanmasına ve bu kasların kendilerine aktarılan tabii uyaranlara yeteri etkinlikte cevap verebilme yeteneğinin bozulması ifade eder (Akgül, 1996; Archeim, 1989; Erkeç, 1973).

Araştırma sonunda elde ettiğimiz veriler doğrultusunda müsabaka süresi arttıkça güreşçilerin sağ-sol el kavrama kuvvetinin azaldığı ve yorgunluğun arttığı tespit edilmiştir. Sonuç olarak; aşırtmalı aba güreşinde el aşırtma tekniğinin kullanılması, güreş müsabakasında harcanan eforun üst ekstremite yorgunluğunu arttırdığını ve 
yorgunluk artışına bağıı olarak uzun süren müsabakalarda performansın olumsuz yönde etkilenebileceği söylenebilir.

Bu çalışma antrenörlerin, güreş ve judo gibi dövüş sporlarında gün içerisinde gerçekleştirilen birbirini izleyen müsabakalar sırasında yorgunluğun performans üzerindeki sonuçlarını daha iyi anlamalarına yardımcı olabilir, yıllık antrenman planlamasında artan müsabaka süresinin yorgunluğu artırdığı göz önünde alınarak planlamaların bu doğrultuda yapılması gerektiği önerilebilir.

\section{Kaynakça}

Ağaoğlu S.A, ve ark. 2001 "Türk Erkek Milli Judo Takım Sporcularının Belirli Fizyolojik Ve Antropometrik Özelliklerinin İncelenmesi. Atatürk Üniversitesi, Beden Eğitimi Ve Spor Bilimleri Dergisi 1.3.

Akgün N. Egzersiz Fizyolojisi. 1996 2. Baskı. İzmir: Ege Üniversitesi Basımevi; 333$343,89$.

Ament, W. Ve Gijsbertus, J.V. 2009. Exercise And Fatigue, Sports Med, 39(5): 369422.

Arnheim D.D. 1989. Modern Principles Of Athletic Training. St. Louis: Mosby Coll. Pub.; 375-385.

Artur M, Robert R, Ewa S.K, Katarzyna K. 2019. Changes in Performance And Morning-Measured Responses In Sport Rock Climbers. Journal Of Human Kinetics Volume 70/2019, 103-114 Dol: 10.2478/Hukin-2019-0050 103.

Avcuoğulları C. 1993 Türkiye Güreş Ligine Katılan Kulüplerin Çalışma Şartları Ve Sporcu Kaynakları, İstanbul Güreş İhtisas Kulübü Koruma Vakfı Yayınları No:6, C Yayınları Matbaası, İstanbul, S. 125

Gurer B, Aksoy Y, Gonulates S, Bicer M, Ozdal M. 2020. Acute Response Of Handgrip Strength, Oxygen Saturation, Heart Rate, And Tactile Discrimination After Rock And Ice Climbing. Acta Medica Mediterranea 36 (3), 1895-1899.

Bonitch-Góngora, Juan G.; Bonitch-Domínguez, Juan G.; Padial, Paulino; Feriche, Belen. 2012 The Effect Of Lactate Concentration On The Handgrip Strength During Judo Bouts. Journal Of Strength And Conditioning Research: July Volume 26 - Issue 7 - P 1863-1871. 
Borges Ng Jr, Domenech Sc, Silva Ack, Dias Ja, Sagawa Junior Y. 2009. Comparative Study Of Maximum İsometric Grip Strength İ Different Sports. Braz J Kineanthropom Hum Perform 11: 292-298.

Chang Hy, Chou Ky, Lin Jj, Lin Cf, Wang Ch. 2010. Immediate Effect Of Forearm Kinesio Taping On Maximal Grip Strength And Force Sense In Healthy Collegiate Athletes. Phys Ther Sport, 11(4), 122-127.

Cutts, A. And Bollen, S.R., 1993. Grip Strength And Endurance In Rock Climbers. Proceedings Of The Institution Of Mechanical Engineers, Cilt:207, Sayı:2, Ss:87-92.

Çalap O, Akın S, Kıınç F, Söyleyici Z.S. 2019. Judocuların Aynı Gün İçinde Gerçekleştirilen Maçlar Arasındaki Kavrama Kuvveti Ve Nabız Seviyelerinin Incelenmesi. International Sport Science Student Studies. Volume: 1 Issue: 1.

Efdal. A., Yamaner. F. 2020. Güreş Ve Halter Sporcularında Antropometrik Özellikler İle El Kavrama Kuvveti Arasındaki İlişkinin İncelenmesi. Çanakkale On Sekiz Mart Üniversitesi Spor Bilimleri Dergisi Cilt.3 Sayı.2 Ss1-11.

Erkeç R.1973. İnsan Anatomi Ve Fizyolojisi. 1. Baskı. Ankara: G.S.B. Eğitim Genel Müdürlüğü Yayınları.

Ersoy G.1991. Sporcu Performansını Araştırmaya Yönelik Beslenme Uygulamaları. Spor Hekimliği Dergisi; 26: 68-69.

Eylen, M. A., Dağlıoğlu, O., Gücenmez, E. 2017. The Effects of Different Strength Training on Static and Dynamic Balance Ability of Volleyball Players. Journal of Education and Training Studies, 5(13), 13-18.

Filiz, K. 1999. Güreşçilerin Maksimal Yüklenme Sonucu Kanda Biriken Laktik Asit Seviyeleri. Beden Eğitimi Ve Spor Bilimleri Dergisi, 1(1), 48-55.

Gabriella S. 1987. Limb Blood Flow İ Prolanged Exercise, Wagnitude And Implicatron For Cardiovascular Control During Muscular Work in Man. Can.J.Sport.Science; 12 : 89-101.

Gandevı, S.G. 2001, Spinal And Supraspinal Factors in Human Muscle Fatigue, Physiol Rev 81: 1725-1789.

Gülke J, Wachter Nj, Katzmaier P, Ebinger T, Mentzel M.2007. Detecting Submaximal Effort In Power Grip By Observation Of The Strength Distribution Pattern. J Hand Surg 32: 677-683. 
Gümüş, M., Barut, Ç. 2006. "Geleneksel Yağlı Güreş Yapan Sporcuların Antropometrik Profillerinin Belirlenmesi”, 9. Uluslararası Spor Bilimleri Kongresi Bildiri Kitabı, Muğla Üniversitesi, Muğla, 2006, Ss. 328-332.

Lermakov S, Podrigalo Lv, Jagiełł W. 2016. Hand-Grip Strength As An Indicator For

Predicting The Success In Martial Arts Athletes. Arc Budo, 12, 179-6.

Iglesias E, Clavel I, Dopico J, Tuimil Jl. 2003 Acute Effect Of The Specific Effort Of Judo On Different Strength Manifestations And Their Relation With The Reached Cardiac Frequency During The Confrontation. $\begin{array}{llll}\text { Rendimientodeportivo.Com, } & 6 & \text { [Digital Journal]. } & \text { Retrieved }\end{array}$ From Http:/Nww.Rendimientodeportivo.Com/N006/Artic027.Htm.

J. Gajewski, E. Hübner-Woźniak, P. Tomaszewski, E. Sienkiewicz-Dianzenza, 2009.

Changes In Handgrip Force And Blood Lactate As Response To Simulated Climbing Competition, Biology Of Sport 26(1),13-21.

Kanbak, Ç. G., Dağlığlu, Ö. 2020. Effect Of Plyometrıc Traınıng Program On Speed And Dynamıc Balance Performances In Volleyball Players. European Journal of Physical Education and Sport Science, 6(9).

Kahraman, A., 1989, Cumhuriyete Kadar Turk Gureşi, No:1029, Ankara, S,17-21

Kalkan, M. K., Daglioglu, O. 2018. The Effects of 8-Week Aerobic Training Program on Respiratory and Circulatory Parameters of Female Swimmers between 1214 Years Old. Journal of Education and Training Studies, 6(12), 202-207.

Keskin, E. 1978. 'Aba Güreşimiz' , S, 16-68, Ankara.

Kim Cr, Jeon Yj, Kim Mc, Jeong T, Koo Wr. 2018. Reference Values For Hand Grip Strength In The South Korean Population. Plos One, 13(4), E0195485.

Koley S, Yadav Mk. 2009 An Association Of Hand Grip Strength With Some Anthropometric Variables In Indian Cricket Players. Phys Educ Sport 7: 113123.

Kraemer Wj, Fry Ac, Rubin Mr, Triplett-Mcbride T, Gordon Se, Koziris Lp, Lynch Jm, Volek Js, Meuffels De, Newton Ru, Fleck Sj. 2001. Physiological And Performance Responses To Tournament Wrestling. Med Sci Sports Exerc 33: 1367-1378.

Koyunlu, A., Dağlığlu, Ö., Özdal, M. 2020. Comparison of Physical Fitness and Respiratory Parameters of Elite Wrestlers and Judokas. Turkish Journal of Sport and Exercise, 22(3), 360-365. 
Koyunlu A, Bilgiç M, Özdal M. (2021). Aşırtmalı Aba Güreşi Müsabakalarında Müsabaka Süresi ile Üst Ekstremite Yorgunluğu Arasındaki İlişkinin İncelenmesi. Gaziantep Üniversitesi Spor Bilimleri Dergisi, 6(4), 413-423.

Leyk, D., Gorges, W., Ridder, D., Wunderlich, M., Rüther, T., Sievert, A., ve Essfeld, D. 2007. Hand-Grip Strength Of Young Men, Women And Highly Trained Female Athletes. European Journal Of Applied Physiology, 99(4), 415-421.

Mancıntosh B.R.1991. Skeletal Muscle Staircase Response With Fatigue Or Dantrolene Sodium. Medicine And Science İn Sports And Exercise; 23(1) : 5663.

Massy-Westropp Nm, Gill Tk, Taylor Aw, Bohannon Rw, Hill Cl. 2011. Hand Grip

Strength: Age And Gender Stratified Normative Data İn A Population-Based Study. Bmc Res Notes, 4, 127.

Maughan, R. Ve Gleeson, M. 2004. The Biochemical Basis Of Sports Performance, Oxford Univrsity Pres.

Moran Ca.1989. Anatomy Of The Hand. Phys Ther 69: 1007-1013.

Nag A, Nag Pk, Desai H. 2003. Hand Anthropometry Of Indian Women. Indian J Med Res, 117, 260-9.

Özer, K. 2013. Fiziksel Uygunluk (4. Baskı). Ankara: Nobel Yayıncılık. S.61-194.

Özer Y, Bozdal Ö, Pancar Z. 2017. Acute Effect of Circuit Aerobıc and Traditional Aerobic Training on Hamstrıng Flexibility in Sedentary Women. European Journal of Physical Education and Sport Science;3(12):268-275.

Pancar Z, Biçer M, Özdal M. 2020. The effect of 8-week plyometric training on anaerobic power, balance and sprint performance of 12-14 aged female handball players. Medicina Dello Sport. March; 73(1):1-10.

Pizzigalli L, Micheletti Cremasco M, La Torre A, Rainoldi A, Benis R. 2017. Hand Grip Strength And Anthropometric Characteristics In Italian Female National Basketball Teams. J Sports Med Phys Fitness, 57(5), 521-528.

R.L. Kons, L.B.D.R. Orssatto, R.L. Sakugawa, J.N. Da Silva Junior, F.Diefenthaeler, D. Detanico, 2020. Effects Of Stretch-Shortening Cycle Fatigue Protocol On Lower Limb Asymmetry And Muscle Soreness In Judo Athletes Sports Biomechanics, Pp. 1-16, 10.1080/14763141.2020.1779335.

R.L. Kons, L.B.R. Orssatto, D. Detanico, 2020. Acute Performance Responses During Repeated Matches İn Combat Sports: A Systematic Review Journal Of Science And Medicine İn Sport, 23, Pp. 512-518, 10.1016/J.Jsams.2019.12.004.

R.L. Kons, Juliano Dal Pupo, Rodrigo G. Gheller, Filipe E. Costa, Matheus M. Rodrigues, Chris Bishop, Daniele Detanico, 2021. Effects Of Successive Judo 
Matches On İnterlimb Asymmetry And Bilateral Deficit. Physical Therapy İn Sport 47, 15-22.

Sande Lp, Coury Hjcg, Oishi J, Kumar S. 2001. Effect Of Musculoskeletal Disorders On Prehension Strength. Appl Ergonom 32: 609-616.

Şahin, H. M. 1999. Gaziantep'te Aşırtmalı Aba Güreşi Üzerine Bir Araştırma. Yüksek Lisans Tezi, Gazi Üniversitesi Sağlık Bilimleri Enstitüsü, Ankara.

Toksöz, İ. 2011. "Bati Trakya Türk Topluluğunun Rodoplardaki Buluşma Noktası", Seçek Yaylası Tarihi Seçek Yağlı Güreşleri Ve Kültür Etkinlikleri. Milli Folklor, 23(91).

Tredgett Mw, Davis Trc. 2000. Rapid Repeat Testing Of Grip Strength For Detection Of Faked Hand Weakness. J Hand Surg 25: 372-375.

Watts P, Newbury V, Sulentic J. 1996. Acute Changes In Handgrip Strength, Endurance, And Blood Lactate With Sustained Sport Rock Climbing. J Sports Med Phys Fitness;36(4):255-60.

Watts, P. B., Joubert, L., Lish, A. K., Mast, J. D., \& Wilkins, B. 2003. Anthropometry Of Young Competitive Sport Rock Climbers. British Journal Of Sports Medicine, 37(5), 420-424.

Yıldıran İ. 1999. Geleneksel Yağlı Güreşin, Kültürel, Yapısal Ve Bilimsel Açıdan Modern Minder Güreşiyle Farklılıklarının Değerlendirilmesi. Gazi Üniversitesi Beden Eğitimi Ve Spor Yüksekokulu, Beden Eğitimi Ve Spor Bilimleri Dergisi, 5(1), S.43-58. 